\title{
Ectopic lymphoid neogenesis in rheumatic autoimmune diseases
}

Michele Bombardieri, Myles Lewis and Costantino Pitzalis

Centre for Experimental Medicine and Rheumatology, 2nd Floor, John Vane Science Centre, William Harvey Research Institute, Barts and the London School of Medicine and Dentistry, Queen Mary University of London, Charterhouse Square, London EC1M 6BQ, UK.

\section{Correspondence to C.P.}

c.pitzalis@qmul.ac.uk

\section{Abstract}

Ectopic lymphoid neogenesis often occurs in the target tissues of patients with chronic rheumatic autoimmune diseases such as: rheumatoid arthritis, Sjögren syndrome and other connective tissue disorders, including systemic lupus erythematosus and myositis. However, the mechanisms of ectopic lymphoid-like structure (ELS) formation and function are not entirely understood. For example, it is unclear whether ELSs indicate distinct disease phenotypes or whether they are evolutionary manifestations of chronic inflammation. Also unclear is why ELSs form in some patients but not in others. Nonetheless, ELSs frequently display functional features of ectopic germinal centres and can actively contribute to the maintenance of autoimmunity through the production of disease-specific autoantibodies; furthermore, they seem to influence disease severity 
and response to both synthetic and biologic DMARDs. In this Review, we discuss current knowledge and gaps in understanding of ELS formation and function including their prevalence in the above rheumatic autoimmune diseases; the mechanisms underlying their formation, maintenance and function, including positive and negative regulatory pathways; their functional relevance in the perpetuation of autoimmunity; their relationship with disease phenotypes, clinical outcomes and response to treatment; and the potential for specific targeting of ELSs through novel therapeutic modalities.

\section{[Main text]}

In order to fulfil the complexity of functions generally referred as immunological responses (including definition of $\mathrm{B}$ and $\mathrm{T}$ cell receptor repertoire diversity, mounting of protective antigen-specific immunity against pathogens, generation and persistency of immunological memory, maintenance of central and peripheral immunological tolerance, etc.) lymphoid tissues have evolutionally differentiated into highly organized structures, which can be broadly classified into primary and secondary lymphoid organs. Primary lymphoid organs comprise the bone marrow and the thymus and are primarily responsible for the selection of naive $\mathrm{B}$ and $\mathrm{T}$ lymphocytes bearing highly diverse B and T cell receptors in their germline sequences. Secondary lymphoid organs (lymph nodes, spleen, mucosal-associated lymphoid tissues such as Peyer's patches) regulate the recirculation of leukocytes and are critical for mounting high-affinity adaptive immune responses upon antigenic challenge.

Tertiary lymphoid organs are defined as clusters of lymphomonocytic cells that form at sites of chronic inflammation in peripheral, non-lymphoid organs - hence they are also known as ectopic lymphoid structures (ELSs) — and they acquire phenotypic features that are characteristic of secondary lymphoid organs. The structures show segregation 
of $\mathrm{T}$ cells and B cells into discrete areas (that is, B-cell follicles surrounded by T cell-rich areas). Furthermore, vascular structures with the appearance of high endothelial venules (HEVs) - specialized postcapillary venous swellings that enable lymphocytes expressing L-selectin to enter from the blood - develop, and networks of stromalderived follicular dendritic cells (FDCs) differentiate; these FDCs express the long isoform of complement receptor type 2 (Cr2, also known as CD21), which contributes to the presentation of immune complexes necessary to generate activated B cells. Plasmablasts and plasma cells subsequently accumulate around the follicles of $\mathrm{T}$ cells and B cells (Figure 1). In addition, a common feature of ELSs is the de novo ectopic expression at sites of inflammation of a discrete set of genes encoding proteins such as lymphoid chemokines and lymphotoxins that are implicated in the development of secondary lymphoid organs. A considerable proportion of ELSs also display functional features of ectopic germinal centres, such as the expression of the enzyme singlestranded DNA cytosine deaminas (also known as activation-induced cytidine deaminase) and evidence of both in situ B cell affinity maturation and clonal selection.

The formation of ELSs is not exclusive to rheumatic diseases, and has been described in other organ-specific autoimmune conditions, during solid tumorigenesis, in chronic infections and in graft rejection, as reviewed elsewhere ${ }^{1}$. However, in the context of this Review, we focus solely on rheumatic autoimmune diseases. Because ELSs most frequently develop in target organs that are sites of chronic, antigen-driven inflammation, most of the information presented herein derives from extensive studies of the synovium of patients with rheumatoid arthritis (RA) and salivary glands of patients with Sjögren syndrome; data regarding the formation of ELSs in the kidneys of patients with systemic lupus erythematosus (SLE) and in the muscle of patients with 
dermatomyositis or polymyositis are more limited. We discuss current knowledge, as well as gaps in our understanding, of ELSs, including their prevalence; the mechanisms underlying their formation, maintenance and function, including positive and negative regulatory pathways; their functional relevance in the perpetuation of autoimmunity; and their relationship with disease phenotypes, clinical outcomes and response to treatment. Finally, the potential for specific targeting of ELSs through novel therapeutic modalities is outlined.

\section{[H1] ELS prevalence and tissue localization}

Although ELSs form in virtually all organ-specific chronic autoimmune diseases, their prevalence ranges from almost $100 \%$ in patients with autoimmune thyroiditis to a small minority of patients with myositis $\mathbf{1}$. The reason underlying such variability is presently unknown, although genetic predisposition, environmental factors and immunosuppressive treatment all probably influence the development and maintenance of ELSs at sites of inflammation.

\section{[H2] Rheumatoid arthritis}

In RA, the activation of resident synovial cells and the synovial microvasculature, together with the infiltration of immune cells from the peripheral pool, leads to chronic proliferative synovitis with the formation of the so-called pannus, which directly damages cartilage and subchondral bone ${ }^{2}$. Advances in our understanding of the complex heterogeneity of the histopathology and the underlying molecular signatures have enabled the definition of at least three microstructural levels of organization 
(pathotypes) of synovial tissue in RA: follicular synovitis with the presence of aggregates of B cells and T cells that form ELSs (lymphoid pathotype); a diffuse pattern of infiltration with prevalent monocyte-macrophage infiltration (myeloid pathotype); and a pauci-immune synovitis with scarce or no immune cell infiltration (fibroid pathotype $)^{3-8}$. Although ELSs primarily form within the sublining of the synovial tissue in patients with RA, they can also be detected at extra-articular sites (including the lung and bone marrow $)^{9}, 10$. ELSs in RA are characterized by the formation, by $\mathrm{T}$ cells and $\mathrm{B}$ cells, of discrete perivascular clusters, which can also be graded (G1, G2 or G3) according to the aggregate radial cell count (the number of cell layers surrounding a central blood vessel) 4, 6,11-14.

It is now generally accepted that ELSs form in approximately $40 \%$ of patients with RA, but this prevalence varies considerably $4,6,8,11-14$ depending on the site of the biopsy, the sampling technique (that is, joint replacement versus arthroscopy versus ultrasound-guided biopsy), the stage of the disease, the treatments received by an individual patient, and the staining and scoring procedure ${ }^{15}$.

\section{[H2] Sjögren syndrome}

Most studies have reported an estimated prevalence of ELSs of 30-40\% for Sjögren syndrome when considering patients who present with a focus score $>1$ in labial salivary gland biopsy samples ${ }^{16-21}$, with similar results obtained from parotid gland tissue samples ${ }^{22}$. ELSs in the salivary glands of patients with Sjögren syndrome form around central ductal structures known as intercalated ducts, which suggests an important role for antigens exposed by ductal epithelial cells in driving the disease. In 
an analysis of almost 500 periductal foci, we demonstrated that approximately $20 \%$ of lymphoid aggregates develop a clear segregation of T cells and B cells in discrete areas as well as networks of FDCs $^{17}$ that are populated by germinal centre B cells and surrounded by perifollicular plasmablasts and plasma cells (supporting functional germinal centre responses) ${ }^{18,23}$, as discussed later.

\section{[H2] Systemic lupus erythematosus}

In one study of patients with SLE, well-defined aggregates of B cells and T cells were observed in the tubulointerstitium in $46 \%$ of kidney specimens from a cohort of 68 individuals with lupus nephritis ${ }^{24}$. Fully formed germinal centres with associated FDC networks occurred less frequently and were observed in only $6 \%$ of patients ${ }^{24}$. In a second study, aggregates of B cells and T cells were found in approximately $60 \%$ of biopsy samples from Chinese individuals with lupus nephritis, but no individuals with CD21+ FDCs could be identified, suggesting that fully organised renal germinal centres are rare in SLE25. Despite the general absence of organised germinal centres, intrarenal lymphoid aggregates in lupus nephritis are surrounded by plasmablasts and express survival factors that promote local B-cell survival and differentiation ${ }^{26}$. Although the formation of ectopic germinal centres within diseased tissues such as the kidney is rarer in patients with SLE than in those with RA, abnormal, accelerated germinal centre formation within the spleen is found during lupus flares both in mouse models of lupus 27,28 and in human patients ${ }^{29}$, and is linked to an excessive type I interferon response, which is a key feature of SLE pathogenesis. Two studies published in 2016 reveal that IFN $\gamma$ signalling is also involved in the spontaneous formation of splenic germinal centres in SLE, a process in which it could activate key pathways implicated in 
autoreactive B-cell development ${ }^{30}, 31$ Thus, both type I and type II interferon-driven aberrant germinal cell formation might function as a common link in the development of autoantibodies and lupus-like autoimmune disease.

\section{[H2] Myositis}

The accumulation of B cells and formation of lymphoid-like structures in autoimmune myositis has long been reported ${ }^{32,33}$ but an in-depth characterization of ELSs and their significance in myositis is lacking. In juvenile dermatomyositis, lymphoid follicles with aggregates of $\mathrm{B}$ cells and $\mathrm{T}$ cells form with a preferential perimysial localization in approximately $20 \%$ of patients ${ }^{34}$, and these follicles can be observed in a relatively small minority of adult patients with myositis ${ }^{35}$. Interestingly, ELSs in myositis do not develop typical germinal centres and generally lack CD21+ FDC networks, suggesting that muscle tissue provides a less permissive environment for lymphoid neogenesis; however, as discussed later, a local, antigen-driven humoral response can still be observed in inflammatory myopathies ${ }^{35,36}$.

\section{[H1] ELS formation, maintenance and function}

The mechanisms that regulate the formation, maintenance and function of ELSs in rheumatic autoimmune diseases are largely shared with those involved in the organogenesis, maintenance and function of secondary lymphoid organs ${ }^{37}$. Conveniently, the factors involved in mediating these mechanisms can be grouped according to their involvement in the different stages of the lymphoid neogenesis process: initiating factors are involved in the early activation of ectopic lymphoid 
neogenesis; propagating factors regulate the progression towards organized lymphoid aggregates, as well as their maintenance; functional factors are involved in the acquisition of features of germinal centres ; and other factors exist that mediate the retention and survival of germinal-centre-derived plasmablasts and plasma cells. Furthermore, with the identification of IL-27 as an inhibitor of ELS development in experimental inflammatory arthritis and $\mathrm{RA}^{38}$, negative regulators of ELSs are beginning to emerge.

\section{[H2] Mediators of initiation and maintenance}

Most mediators that are involved in the initiation of lymphoid neogenesis are also involved in the maintenance of the resulting lymphoid tissue, but the cellular sources of these mediators seem to be distinct in the early versus late stages of ELS formation. Furthermore, although increasing evidence indicates that the formation of ELSs in the inflamed microenvironment of rheumatic autoimmune diseases (for instance, the synovium in RA, salivary glands in Sjögren syndrome or kidneys in SLE) does not necessarily follow the pre-programmed ontogenic processes that regulate the development of secondary lymphoid organs owing to the contribution not only of infiltrating immune cells but also of tissue-specific cell types (Table 1), we will nevertheless use secondary lymphoid organ organogenesis as a reference when discussing ELS formation, highlighting the similarities and differences between these two processes.

\section{[H3] Lymphotoxin- $\beta$ and lymphoid chemokines.}

The initiation of lymphoid neogenesis and its maintenance during the formation of ELSs or secondary lymphoid organs requires the ectopic expression, in a manner 
largely dependent on lymphotoxin- $\beta$ (LT- $\beta$ ), of homeostatic lymphoid chemokine CXCchemokine ligand 13 (CXCL13, which binds to its unique receptor, CXCR5), and CCLchemokine ligand 19 (CCL19) and CCL21 (which engage CCR7). During lymphoid organogenesis, the formation of the lymphotoxin-lymphoid chemokine feedback loop is driven by the interaction during embryogenesis between haematopoietic cells such as $\mathrm{CD}^{-} \mathrm{CD} 4{ }^{+} \mathrm{IL}-7 \mathrm{R}^{+} \mathrm{RANK}^{+}$lymphoid tissue inducer cells and/or (their relative importance being related to the site of lymphoid organ development) CD3 $^{-C D} 4^{-}$ CD45+IL-7Ra-RANK ${ }^{+}$CD11 $\mathrm{c}^{+} \mathrm{CD} 11 \mathrm{~b}^{+}$lymphoid tissue initiator cells with VCAM1+ICAM1+LT $\beta R^{+}$mesenchymal organizer cells 39-41. Briefly, lymphoid tissue inducer cells receive activating signals from mesenchymal organizer cells in the presence of CXCL13, IL-7 and RANK ligand (RANKL, also known as TNFSF 11); these activating signals regulate the migration and survival of lymphoid tissue inducer cells and, critically, their expression of membrane-bound heterotrimeric LT $\beta$ (LT $\alpha 1 \beta 2)$, a member of the TNF family. The interaction of LT $\alpha 1 \beta 2$ with LT $\beta$ receptor (LT $\beta R$ ) expressed on mesenchymal organizer cells triggers the production of the lymphoid chemokines CXCL13, CCL19 and CCL21, and is also critical for promoting the differentiation of HEVs ${ }^{42}$. In agreement with the notion that ELS development is controlled by reactivation at ectopic sites of the same pathways involved in the organogenesis and homeostasis of secondary lymphoid organs, the expression of lymphoid chemokines CXCL13 and CCL21 correlates strongly with the presence of ELSs in rheumatic autoimmune diseases. We and others have shown that the expression of lymphoid chemokines increases with the progressive acquisition of lymphoid features in the synovium of patients with RA and the salivary glands of patients with Sjögren syndrome, 5, 6, 8, 17, 43-45 suggesting that these chemokines have an upstream role in ELS development. The expression of CXCL13 and CCL21 in ELSs is generally confined to the 
B-cell-rich and the T-cell-rich areas of the ectopic follicles, respectively, as occurs in secondary lymphoid organs ${ }^{6,17}$. However, during chronic inflammation in ELSs, it seems that additional alternative cell types can express lymphoid chemokines. Within RA and Sjögren syndrome lymphoid aggregates, myofibroblast-like stromal cells primarily express CCL21, similar to the scenario observed in lymph nodes in adult life where CCL21 is mostly expressed by fibroblastic reticular cells in the T-cell rich area 46,47 whereas infiltrating immune cells, including $\mathrm{CD}_{14^{+}}$inflammatory monocytes, CD68+ macrophages and memory $\mathrm{CD} 3^{+} \mathrm{CD} 4^{+} \mathrm{T}$ cells, express CXCL13 ${ }^{48-51}$. The expression of CXCL13 by monocyte-derived cells concurs with evidence that the maintenance and function of ELSs are dependent on the influx of CD11b+CD11 $c^{+}$dendritic cells producing CXCL13, CCL19 and CCL21 during the formation of influenza-virus-driven inducible bronchus-associated lymphoid tissue (iBALT) ${ }^{52}$. In the presence of functional germinal centres, CXCL13 is primarily released by stromal-derived FDCs ${ }^{6,8}, 17$. Resident nonimmune cells can also be a source of CXCL13, as demonstrated for ductal epithelial cells and endothelial cells in the salivary glands of patients with Sjögren syndrome ${ }^{17,44,53,54}$.

\section{[H3] Proinflammatory cytokines}

As ELSs form at inflammatory sites, it is not surprising that proinflammatory cytokines have emerged as important contributors to the development of ELSs in addition, or as alternative pathways, to the classical lymphotoxin-induced lymphoid neogenesis. A role for the IL-23-IL-17 pathway in the development of ELSs in animal models of relapsingremitting multiple sclerosis and in the lungs during the development of iBALT has been demonstrated ${ }^{55}$, 56. Interestingly, in the context of ELS development, IL-17 can be produced by cells of both the innate and adaptive arms of the immune system, suggesting that this cytokine might be involved both in the initiation and perpetuation 
of ELSs. Specifically, a subset of adult innate lymphoid cells (type 3 innate lymphoid cells (ILC3 cells)) can produce IL-17 during the initial steps of ELS formation; 57 and specific subsets of $\mathrm{T}$ helper $17\left(\mathrm{~T}_{\mathrm{H}} 17\right)$ cells contribute to ELS development in experimental autoimmune encephalomyelitis, a mouse model of multiple sclerosis 55 . Consistent with the above observations, which implicate IL-17 in ELS formation, IL-17 is mostly produced by $\mathrm{CD}^{+} \mathrm{T}$ cells in synovial tissue from patients with $\mathrm{RA}$; $\mathrm{T}_{\mathrm{H}} 17$-like cells can frequently be observed within and adjacent to ELSs in these samples ${ }^{58}$. Additionally, activation of the IL-23-IL-17 pathway correlates with the presence of synovial ELSs in patients with RA ${ }^{59}$.

In addition to IL-17, IL-22, a member of the IL-10 superfamily (comprehensively reviewed elsewhere ${ }^{60}$ ), is reported to be required for the development and maintenance of ELSs ${ }^{61}$ that form in the salivary glands in a mouse model of virus-induced lymphoid neogenesis, which displays several features of human Sjögren syndrome ${ }^{62}$. In this experimental model, IL-22 directly induces the production of CXCL13 in a subset of GP38 $^{+}$stromal cells through phosphorylation of signal transduced and activator of transcription 3 (STAT3); Il22/- mice were protected from ELS development and autoimmunity through reduced B-cell recruitment to the salivary glands ${ }^{61}$. Notably, although IL-22 was mostly produced by $\gamma \delta$ T cells and ILC3-like cells within hours of viral infection, by 5 days post-infection most IL-22 production was dependent on classical $\alpha \beta$ T cells ${ }^{61}$. It is currently unclear whether IL-22 is capable of inducing ELSs in the absence of LT $\beta$, and whether IL-22 also has a role in the maintenance of ELSs in rheumatic autoimmune diseases. Reports of increased IL-22 expression in CD21L+ cells in synovial tissue from patients with $\mathrm{RA}^{59}$ and of IL-22 production by $\mathrm{T}_{\mathrm{H}} 17$-like and $\mathrm{NKp}_{4} 4^{+}$natural killer cells in the salivary glands of patients with Sjögren syndrome ${ }^{63}$ 
would suggest that persistent IL-22 expression also contributes to the maintenance of ELSs

The evidence outlined above reinforces the concept that whereas innate immune cells are critical in controlling the initiation of lymphoid neogenesis, cells of the adaptive immune system within days become capable of releasing key mediators that are critical for the progression and maintenance of ELSs.

\section{[H2] Mediators of ELS function}

In order to fulfil their role as functional germinal centres, thus promoting antigendriven selection of B cell clones via affinity maturation, ELSs require a series of factors, both soluble (that is, certain cytokines) and membrane-bound (that is, receptor-ligand interactions), able to activate the molecular machinery required for immunoglobulin somatic hypermutation and classswitching. These factors are largely provided by specialized T helper cell subsets migrating into the B cell follicles.

\section{[H3] T follicular helper cells}

$\mathrm{T}$ follicular helper $\left(\mathrm{T}_{\mathrm{FH}}\right)$ cells are a distinct and highly specialized $\mathrm{CD} 4^{+} \mathrm{CXCR} 5^{+}$memory $\mathrm{T}$ helper cell subset. In the context of ELSs, the best example of a critical role of $\mathrm{T}_{\mathrm{FH}}$ cells in the function of ectopic germinal centres comes from Mycobacterium tuberculosisinduced iBALT, in which these cells are vital in controlling the clearance of pathogens ${ }^{64}$. 
The development of functional germinal centres is largely dependent on an antigendriven immune response and requires cognate interactions between T cells and B cells 65. In response to CXCL13 produced by FDCs in germinal centres ${ }^{66}, \mathrm{~T}_{\mathrm{FH}}$ cells localize to B-cell follicles where they have a non-redundant role in B cell activation, antibody affinity maturation and germinal centre reactions. Cognate interactions between $\mathrm{T}_{\mathrm{FH}}$ cells and B cells are critically dependent on interactions between inducible T-cell costimulator (ICOS) and its ligand, ICOSL, and between CD40 (also known as TNFRSF5) and its ligand, CD40L, and the release of IL-21, a potent cofactor for B-cell survival, proliferation and plasma-cell differentiation, particularly in the context of CD40 costimulation and in synergy with B-cell-activating factor (BAFF, also known as TNFSF13B) ${ }^{67,68}$. (Figure 2)

Accumulating evidence implicates IL-21 and $\mathrm{T}_{\mathrm{FH}}$ cells in the development of ELSs in rheumatic autoimmune diseases, particularly in Sjögren syndrome and RA. Upregulated expression of IL-21 and its receptor, IL-21R, has been reported in synovial tissue from patients with RA, ${ }^{69}, 70$ and IL-21 expression closely correlates with the formation of ELSs in this context ${ }^{38}$. Additionally, blockade of IL-21R signalling using a fusion protein considerably ameliorates disease progression in animal models of RA, ${ }^{71}$ and IL-21 downregulation using intra-salivary-gland delivery of a short hairpin RNA directed against IL-21 significantly improves disease outcome in the nonobese diabetic (NOD) mouse model of Sjögren syndrome, which is characterized by the formation of $\mathrm{ELSs}^{72}$. Interestingly, in salivary glands from patients with Sjögren syndrome, the direct interaction of naive $\mathrm{CD}^{+}$cells with activated epithelial cells might promote $\mathrm{T}_{\mathrm{FH}}$ cell differentiation and IL-21 production ${ }^{73}$.

\section{[H2] Turning off ELS development}


Given the importance of $\mathrm{T}_{\mathrm{H}} 17$ cells and $\mathrm{T}_{\mathrm{FH}}$ cells in the maintenance and function of ELSs, factors with the potential to alter the fate of these cells might also influence ELS development. In this regard, IL-27 has been shown to regulate adaptive immunity and to limit $\mathrm{T}$-cell-dependent immunopathology by restricting the expansion of $\mathrm{T}_{\mathrm{H}} 17$ cells $^{74}$. In collaboration with the Jones group, we reported that $1127 \mathrm{ra}^{-/-}$mice develop a more severe form of antigen-induced arthritis, characterized by the development of multiple lymphoid aggregates in the inflamed synovium, in response to immunization with methylated bovine serum albumin ${ }^{38}$. In parallel, increased numbers of $\mathrm{T}_{\mathrm{H}} 17$ cell in the draining lymph nodes and a concomitant increase in serum levels of IL-17 were observed, suggesting that in this system IL-17 secretion and $\mathrm{T}_{\mathrm{H}} 17$ cell differentiation are under the control of IL-2738. Furthermore, when translating these observations into the human setting, we observed that the levels of IL-27 in synovial tissue from patients with RA correlated inversely with ELS development, the degree of synovial infiltration of $\mathrm{CD}^{+} \mathrm{T}$ cells and $\mathrm{CD} 20^{+} \mathrm{B}$ cells, and the expression of IL-17-encoding and IL-21encoding transcripts ${ }^{38}$. Finally, gene therapy with IL-27 ameliorates Sjögren syndromelike autoimmune exocrinopathy in mice ${ }^{75}$.

By contrast, in pristane-induced glomerulonephritis (a mouse model that recapitulates some features of SLE), IL-27 supports germinal centre function and autoantibody production in secondary lymphoid organs by enhancing the production of IL-21 and the function of $\mathrm{T}_{\mathrm{FH}}$ cells ${ }^{76}$. These discordant findings could result not only from intrinsic differences in the role of IL-27 in regulating ELSs versus secondary lymphoid organ responses, but also from the relevance of the same factors to modulating $\mathrm{CD}^{+}{ }^{+} \mathrm{T}$-cell plasticity under different experimental conditions and in different inflammatory microenvironments. Nonetheless, investigating the mechanisms that are involved in turning off ELSs represents an important research area, as a better 
understanding of this phenomenon might lead to the development of new therapies that are capable of targeting these highly pathogenic structures. In this regard, the identification of $\mathrm{T}$ follicular regulatory cells and their capacity to regulate germinal centre responses in secondary lymphoid organs ${ }^{77}$ is likely to prove relevant for ELS function.

\section{[H1] ELSs and autoimmunity}

As described above, ELSs in rheumatic autoimmune diseases recapitulate the cellular, molecular and structural organization of secondary lymphoid organs and can also display features of functional germinal centres. Not surprisingly, therefore, they can facilitate he affinity maturation of germinal centre B cells through antigen-driven selection and their differentiation into (auto)antibody-producing cells.

\section{[H2] Affinity maturation}

Microdissection of ectopic germinal centres or isolated B cells from ELS-positive tissues (such as the synovium of patients with RA, the salivary glands of those with Sjögren syndrome or the kidneys of those with SLE) has shown conclusively that IgG-producing, IgA-producing and some IgM-producing B-cell clones that populate ELSs display highly somatically hypermutated immunoglobulin variable heavy chain $\left(\mathrm{V}_{\mathrm{H}}\right)$ and light chain $\left(\mathrm{V}_{\mathrm{L}}\right)$ genes, consistent with their antigen-driven selection $20,24,78,79$. Mutations that accumulate in hotspots within the complementarity-determining region of the immunoglobulin $\mathrm{V}_{\mathrm{H}}$ and $\mathrm{V}_{\mathrm{L}}$ genes are physiologically acquired by B cells in the germinal centres of secondary lymphoid organs through the process of immunoglobulin gene 
somatic hypermutation (Figure 2). Lineage-tree analysis of the immunoglobulin gene repertoire of B cells and perifollicular plasmablasts and plasma cells that populate ELSpositive tissue from patients with RA, Sjögren syndrome or myositis has demonstrated the presence of a clonal relationship between B cells and surrounding plasmablasts and plasma cells, confirming that intra-tissue clonal diversification and differentiation into antibody-producing cells can occur within ectopic germinal centres $20,35,78,79$. Furthermore, although B cells and plasmablasts that have already undergone hypermutation (that is, they have probably been primed in secondary lymphoid organs) can also migrate from the peripheral compartment and enter chronically inflamed tissues in rheumatic autoimmune diseases, in the absence of ELSs with functional germinal centres these cells do not seem to undergo any further functional diversification as they fail to accumulate further somatic mutations ${ }^{79}$. Consistent with the above evidence, ELSs are required for B-cell affinity maturation at ectopic sites, as the expression of activation-induced cytidine deaminase (AICDA, also known as singlestranded DNA cytosine deaminase), an enzyme involved in somatic hypermutation (but also in class-switch recombination, which is responsible for immunoglobulin isotype switch and influences antibodies effector function), is restricted to ELS-positive tissue in the synovium of patients with RA and in the salivary glands of patients with Sjögren syndrome, and closely correlates with the presence of CD21+ FDC networks and the mRNA-level expression of the FDC-specific gene $C D 21 L^{4,43,80,81 .}$

\section{[H2] Antigen-driven disease-specific autoimmunity}

Critically, ectopic germinal centres are also intimately linked with the local production of autoantibodies and thus have been implicated in the perpetuation of autoimmunity within the target organ, although this notion has been challenged in the field of 
inflammatory arthritis on the basis of two lines of evidence. First, ELSs can be found in patients with 'seronegative' (that is, with no anti-citrullinated protein antibodies (ACPAs) or rheumatoid factor (RF)) arthritides, such as spondyloarthropathies. ${ }^{82,} 83$ Second, the presence of synovial ELSs does not correlate with the levels of circulating or synovial fluid ACPAs ${ }^{12,83,84}$ (but systemic or synovial fluid detection of ACPAs does not necessarily reflect local production in synovial ELSs and is influenced by production at extra-articular sites such secondary lymphoid organs).

Conversely, however, a large body of evidence corroborates the notion that functional germinal centres do indeed contribute to the perpetuation of local autoimmunity to disease-associated autoantigens. Synovial protein extracts from ELSpositive RA tissues are significantly enriched in both IgM RF and IgG ACPAs ${ }^{85}$, and the engraftment of ELS-positive (but not ELS-negative) synovial tissue from patients with RA into severe combined immunodeficiency (SCID) mice in a human-mouse chimeric model resulted in the release of human class-switched ACPAs into the mouse circulation ${ }^{4}$. Additionally, within the synovium of patients with RA, perifollicular $\mathrm{CD}_{138}{ }^{+}$plasma cells frequently display immunoreactivity against citrullinated antigens (Figure 3). Using an unbiased approach based on single B-cell sorting, cloning and recombinant monoclonal antibody production from ACPA ${ }^{+}$ELS-positive synovia or from synovial fluid from patients with RA, we and others have demonstrated that $>30 \%$ of the overall synovial B-cell response is directed towards citrullinated antigens in some patients 78,86 , supporting the concept that an enriched selection of ACPA-producing B cells occurs within synovial ELSs in RA. Interestingly, the ACPA response in ELSs is not limited to the joints of patients with RA but can also take place in the lung in those patients with pulmonary involvement ${ }^{10}$. 
Similar data have emerged from studies of ectopic germinal centes developing in the salivary glands of patients with Sjögren syndrome. In this context, a large number of autoreactive $\mathrm{CD} 138^{+}$plasma cells accumulate at the border of B-cell follicles, which are characterized by CD21+ FDC networks and populated by AICDA+ germinal centre B cells. These cells are frequently reactive towards Sjögren syndrome-associated autoantigens such as the ribonucleoproteins Ro/SSA and La/SSB ${ }^{18,44}$ (Figure 3). Similar to the above evidence, the prevalence of circulating anti-Ro/SSA and anti-La/SSB antibodies is on average $\sim 20 \%$ higher in patients with Sjögren syndrome in whom ELSs are present compared with those without ELSs ${ }^{87}$.

Thus, ELSs in rheumatic autoimmune diseases effectively fail to exert physiological mechanisms of tolerance that regulate the follicular exclusion of autoreactive B cells, thereby allowing the differentiation of these cells into high-affinity autoreactive plasma cells ${ }^{81}$.

Notably, although the processes underlying the formation of ELSs in the synovium of patients with RA and the salivary glands of those with Sjögren syndrome are similar, the antigen-driven autoimmune response within ELSs in their respective target organs seems to be disease-specific (Figure 3).

Direct evidence for this phenomenon comes from in vivo experiments in the chimeric SCID mouse-human model in which engraftment of ELS-positive synovium from patients with RA or from the salivary glands of patients with Sjögren syndrome leads to the release of ACPAs and of anti-Ro/SSA and anti-La/SSB human IgG, respectively, but not vice versa ${ }^{18,88}$. However, the exact nature of the (auto)antigen(s) that fuel the (auto)reactive immune response in rheumatic autoimmune diseases remains elusive. In particular, it is unclear whether immunodominant epitopes across 
different patients are responsible for driving most of the antigen selection process within ectopic germinal centres, and whether a process of epitope spreading accompanies the dynamic evolution of autoimmune responses at sites of chronic inflammation. Nevertheless, the identification that dominant B-cell clones with frequent autoreactive immunoglobulin variable regions (but also dominant T-cell clones) represent a significant proportion of the synovial B-cell (and T-cell) diversity within the tissue and across different joints strongly favours the hypothesis that dominant (auto)antigens indeed exist ${ }^{89}, 90$. High-throughput immunoglobulin gene sequencing in combination with the identification of the fine specificity of recombinant monoclonal antibodies derived from lesional B cells and plasma cells in rheumatic autoimmune diseases might clarify the nature of these dominant autoantigens and potentially pave the way for tolerogenic strategies.

\section{[H2] Plasma cell survival}

Once autoreactive plasma cells are generated in ELSs or have migrated from the peripheral compartment, an important feature of rheumatic autoimmune diseases is their capacity to promote retention of these cells within the target tissue. Plasma-cell survival in bone-marrow niches depends on signals received through adhesion molecules and a series of soluble factors, most notably CXCL12, IL-6 and a proliferationinducing ligand (APRIL, also known as TNFSF13) ${ }^{91}$. Not surprisingly, high levels of factors involved in plasma cell retention and survival have been described in rheumatic autoimmune diseases with focal lymphocytic aggregates. Szyszko et al. ${ }^{92}$ demonstrated the abundant expression of CXCL12 and IL-6 in labial salivary gland biopsy samples from patients with Sjögren syndrome with high focus score (that is, extensive lesions) and high infiltration of CD138+ cells. Similarly, we reported high levels of CXCL12 in 
ductal epithelial cells and CD68+ cells in the salivary glands of patients with Sjögren syndrome with $\mathrm{ELSs}^{48}$. In RA, fibroblast-like synoviocytes seem to have a fundamental role in plasma cell survival. Synovial stromal cells, but not dermal stromal cells, constitutively release high levels of APRIL ${ }^{80}$, and the survival of autoreactive plasma cells in ELS-positive RA synovial grafts from patients with RA in the SCID-RA chimera model is strongly associated with the persistent expression of APRIL ${ }^{4}$. Additionally, stromal cells from the synovia of patients with RA can release high amounts of CXCL12 in response to IL-17,93 and polymorphisms in the promoter of the gene encoding IL-6 cause high IL-6 expression in this cell type ${ }^{94}$. Further elucidation of the above mechanisms might prove relevant not only for understanding disease pathogenesis, but also for disease outcome, as the number of lesional $\mathrm{CD}_{138^{+}}$cells have emerged as potentially important predictors of response to biologic therapy, as discussed below.

\section{[H1] ELSs and disease severity}

\section{[H2] Rhematoid arthritis}

The relevance of synovial ELSs to disease severity in RA is controversial. Several studies have reported that ELSs are associated with increased circulating levels of inflammatory markers and inflammatory cytokines, autoantibody status, higher disease severity and higher erosive load,5, 43, 95, 96 whereas other reports have failed to find a direct correlation between the presence of ELSs and the disease activity score, autoantibody status and presence of erosive disease ${ }^{12,}$ 97. Several factors could contribute to these conflicting results, including inconsistent definitions of ELSs, differences in cohort size or disease duration, and prior exposure to DMARDs and/or biologic therapies. ${ }^{15}$ Thus, 
in order to progress the field it is critical that the potential clinical use of synovial pathotypes in RA is further investigated in multicentre investigations based on a consensus definition of ELS and in homogenous patient cohorts.

\section{[H2] Sjögren syndrome}

Evidence for a role of ELSs in disease progression is more robust for Sjögren syndrome than for RA. The presence of ELSs in the salivary glands of patients with Sjögren syndrome is associated with higher levels of circulating autoantibodies and systemic manifestations, including lymphadenopathy and peripheral neuropathy $18,21,44,87$. Approximately 5\% of patients with Sjögren syndrome will develop non-Hodgkin B-cell lymphomas of mucosal-associated lymphoid tissue (MALT-L), most commonly arising in the parotid glands ${ }^{98}$. In Sjögren syndrome, evidence exists that neoplastic B-cell clones originate from common precursors that often display variable immunoglobulin domains with homology to RF 99,100 , which is already present during the polyclonal phase of the local humoral response. These clones are progressively enriched during the progression first to lymphoepithelial lesions and then to MALT-L, ${ }^{101}$ suggesting that MALT-L in Sjögren syndrome is an (auto)antigen-driven process. We reported in 2007 that the prevalence of ELSs in labial salivary gland biopsy samples was extremely high (over $75 \%$ ) in patients with Sjögren syndrome who later developed parotid MALT-L ${ }^{23}$. Subsequent studies established that the presence of ELSs in labial salivary glands at diagnosis conferred a 16-fold increased risk of lymphoma $21,87$.

\section{[H2] SLE}


In SLE, only limited data associate the presence of renal ELSs with clinical severity. However, existing evidence suggests that the presence of renal B-cell aggregates and plasma cells is more commonly seen in patients with diffuse proliferative lupus nephritis (class IV) and membranous disease either alone (class V) or in combination with focal (classes III and IV) or diffuse (classes IV and V) proliferative nephritis than in those with less severe types of lupus nephritis, and might be associated with greater SLE disease activity and more severe renal impairment $25,102$.

\section{[H1] ELSs and the response to biologic therapies}

\section{[H2] TNF inhibitors}

Several studies have investigated the correlation between the presence of synovial ELSs and the response to TNF inhibitors in RA. Again, the results are conflicting. Some reports showed that the presence of ELSs predicted a positive response to infliximab ${ }^{103}$ whereas ELSs emerged as negative independent predictors of clinical improvement in other studies ${ }^{84}$. These discordant data might partly be reconciled by the demonstration in post-treatment analysis that the disruption of ELSs after TNF inhibition is selectively associated with a positive clinical response, whereas their persistence is not ${ }^{84}$.

\section{[H2] Rituximab}

Several studies investigated the link between clinical response and ELSs in patients with RA or Sjögren syndrome treated with the anti-CD20 monoclonal antibody rituximab. Interestingly, although no association between the change in synovial B cell number from baseline and clinical response to rituximab treatment has been observed in patients with $\mathrm{RA}^{104}$, in sequential parotid gland biopsy samples taken from patients 
with Sjögren syndrome at baseline and 12 weeks after starting treatment with rituximab, the median number of $\mathrm{CD}^{2} 0^{+} \mathrm{B}$ cells emerged as a positive predictor of clinical improvement ${ }^{105}$. Of note, although rituximab treatment invariably eradicates B cells from the peripheral circulating pool and significantly reduces the number of lesional $\mathrm{CD}^{2} 0^{+}$cells, niches of $\mathrm{B}$ cells and plasma cells that escape depletion are frequently observed in ELSs in the salivary glands of patients with Sjögren syndrome and the synovia of patients with $\mathrm{RA}^{11}, 13,85,106-108$. Additionally, the persistent accumulation of plasmablasts and plasma cells and the early repopulation of B cells after depletion are commonly observed in ELSs in patients with RA or Sjögren syndrome $13,85,106$, and in RA plasma cells persistence is associated with a poorer clinical response to rituximab 108,109 . Importantly, in patients with RA, circulating levels of CXCL13, which are associated with the presence of synovial ELSs ${ }^{3}$, strongly predict the degree of peripheral B cell repopulation 6 months following rituximab treatment. ${ }^{110}$ This result again suggests that ELSs can influence the rate of B cell depletion and repopulation at the tissue level after rituximab treatment.

\section{[H2] Abatacept}

As described above, the function of ELSs is critically dependent on interactions between cognate T cells and B cells, so treatment with abatacept (a CTLA4-IgG1 fusion protein that inhibits interactions between CD80/CD86 on antigen-presenting cells (APCs), including B cells, and CD28 on T cells) would be expected to potentially influence ELS survival. However, only a mild reduction in the number of synovial B-cell follicles has been reported in patients with RA treated with abatacept following an inadequate response to either TNF inhibition ${ }^{111}$ or rituximab, ${ }^{112}$ or in pilot studies in patients with Sjögren syndrome ${ }^{113}$. However, rather than promoting the physical disruption of ELSs, 
abatacept (or other novel biologic agents targeting $\mathrm{T}$ cell-B cell co-stimulation, as discussed in the final section) might instead mainly influence the functionality of ELSs and their capacity to fine-tune T-cell responses and the function of ectopic germinal centres.

\section{[H1] ELSs as new therapeutic targets}

Advances in our understanding of the mechanisms regulating the formation, maintenance and function of ELSs, and the increased appreciation of their importance in disease pathogenesis and response to treatment, as described above, have provided a strong rationale for targeting these structures in rheumatic autoimmune conditions for therapeutic purposes. Several compounds entering the clinical arena have the potential to interfere with ELS formation, maintenance and function (Table 2).

The main challenge in devising an effective strategy to disrupt ELS architecture and/or function relates to the observed differences in the mechanisms regulating ELSs at different stages of the lymphoid neogenesis process - that is, from initiation to propagation and maintenance and finally to the development of functional ELSs. Thus, evidence gathered from experimental animals in which early stages of ELS formation are targeted generally (ELS prevention strategies through either gene depletion or pharmacologic blockade) might not necessarily translate into successful application in randomized clinical trials. For example, although pharmacologic inhibition of LT $\beta$ using a LT $\beta$ R-Ig fusion protein results in ELS impairment and disease amelioration in experimental arthritis ${ }^{114}$ and in animal models of Sjögren syndrome, ${ }^{115}$ randomized 
clinical trials with baminercept- $\alpha$ (a fusion protein of human LT $\beta$ R and human IgG1) failed to demonstrate clinical efficacy in RA or, in preliminary analyses reported at the 2015 ACR meeting, in Sjögren syndrome ${ }^{116}$. Nevertheless, neither study stratified patients on the basis of the presence of ELSs and, as such, probably included a considerable number of patients in whom the lymphoid neogenesis process was inactive. Blocking pathways of ELS initiation that are alternative to, and possibly independent from, LT $\beta$, such as IL-17 and IL-22, also represents an attractive strategy. A plethora of promising compounds targeting IL-17 are currently undergoing clinical testing in ELS-positive rheumatic diseases but their impact on ELSs is currently untested. Notably, as for the baminercept studies, it will be essential to stratify patients according to target activity in the disease tissues, as some of the disappointing results seen with IL-17 blockade in RA might, once again, be related to the fact that this pathway is active in the joint in only $30-40 \%$ of patients with RA and is associated with the presence of synovial ELSs 59 .

Inhibition of co-stimulation of $\mathrm{T}_{\mathrm{FH}}$ cell-B cell interactions through the blockade of ICOSL-ICOS, CD40L-CD40 or IL-21-IL-21R interactions could considerably alter ELS function and downstream autoreactive B-cell activation. Pharmacologic blockade of ICOS, as well as inhibition of the signature $\mathrm{T}_{\mathrm{FH}}$-cell cytokine, IL-21, have proven beneficial in experimental arthritis ${ }^{71}$, Sjögren syndrome-like sialoadenitis ${ }^{72}$ and mouse lupus-like disease ${ }^{117}$. Blocking agents that target ICOSL, CD40 and IL-21 have entered early-phase clinical trials for ELS-positive rheumatic autoimmune diseases, but the results are currently unavailable.

Although a beneficial role for histopathology in predicting the clinical response to specific biologic drugs currently lacks sufficient evidence, the addition of a detailed 
histopathological and molecular characterization of ELS-related pathways in clinical studies could not only provide information about target validation and patient stratification, but also identify additional factors that are potentially contributing to the failure of novel (and existing) biologic drugs in modulating ELS function in rheumatic autoimmune diseases. For example, these agents might be ineffective at modulating other dominant mediators associated with ELSs (such as the IL-23-IL-17 and IL-21 pathways). ${ }^{38,59}$ Alternatively, or in addition, an alternative cytokine drive might emerge following pathway blockade (for example, a $\mathrm{T}_{\mathrm{H}} 17$ cell-mediated increase in IL-17 following TNF inhibition ${ }^{113,118}$. Furthermore inadequate target elimination in protected ELS niches could occur, thus requiring more refined strategies for delivering therapeutic agents to the site of inflammation ${ }^{119}$.

\section{[H1] Conclusions}

The study of ELSs in rheumatic autoimmune diseases over the past 10 years has provided important new insights into the mechanisms that link chronic inflammation and the perpetuation of autoimmunity. The elucidation of the cellular sources of key factors that drive the formation of ELSs in rheumatic autoimmune diseases has highlighted critical differences in the regulation of lymphoid neogenesis in adults compared with lymphoid organogenesis that occurs during embryonic development. Furthermore, the demonstration that ELSs can act as functional germinal centres and support antigen-driven autoreactive B cell activation has paved the way for further studies investigating the fine specificity of lesional B cells at the single-cell level; these studies have the potential to reveal new insights into the dominant antigens that drive disease-specific autoimmune responses, with the prospect of future tolerogenic studies in patients with rheumatic autoimmune diseases. Finally, the availability of novel 
compounds that target specific factors that act at different steps during the formation and function of ELSs will clarify whether the direct targeting of ELSs is a feasible and beneficial therapeutic strategy and is able to prevent disease progression - for example, B cell lymphoma development in patients with Sjögren syndrome. To effectively advance the field, it is essential that current and future studies investigating novel ELS-blocking strategies are not limited to the assessment of clinical improvement, but are accompanied by refined mechanistic studies at sites of ELS formation that encompass the fine-tuning of T-cell responses, the impact on ectopic germinal cell functionality and the inhibition of autoreactive B-cell activation. Finally, we envisage that a better understanding of the histopathological heterogeneity in the target tissue of rheumatic autoimmune diseases and the underlying molecular signatures might lead to the identification of specific biomarkers that, once validated in larger cohorts of patients and in randomized studies, would allow patients to be stratified prior to treatment initiation.

1. Pitzalis, C., Jones, G.W., Bombardieri, M. \& Jones, S.A. Ectopic lymphoid-like structures in infection, cancer and autoimmunity. Nat Rev Immunol 14, 447-62 (2014).

2. McInnes, I.B. \& Schett, G. The pathogenesis of rheumatoid arthritis. N Eng/ J Med 365, 220519 (2011).

3. Dennis, G., Jr. et al. Synovial phenotypes in rheumatoid arthritis correlate with response to biologic therapeutics. Arthritis Res Ther 16, R90 (2014).

4. Humby, F. et al. Ectopic lymphoid structures support ongoing production of class-switched autoantibodies in rheumatoid synovium. PLoS Med 6, e1 (2009).

5. Klimiuk, P.A., Goronzy, J.J., Bjor nsson, J., Beckenbaugh, R.D. \& Weyand, C.M. Tissue cytokine patterns distinguish variants of rheumatoid synovitis. Am J Pathol 151, 1311-9 (1997).

6. Manzo, A. et al. Systematic microanatomical analysis of CXCL13 and CCL21 in situ production and progressive lymphoid organization in rheumatoid synovitis. Eur J Immuno/ 35, 1347-59 (2005).

7. Pitzalis, C., Kelly, S. \& Humby, F. New learnings on the pathophysiology of RA from synovial biopsies. Curr Opin Rheumatol 25, 334-44 (2013).

8. Takemura, S. et al. Lymphoid neogenesis in rheumatoid synovitis. J Immunol 167, 1072-80 (2001).

9. Bugatti, S. et al. Involvement of subchondral bone marrow in rheumatoid arthritis: lymphoid neogenesis and in situ relationship to subchondral bone marrow osteoclast recruitment. Arthritis Rheum 52, 3448-59 (2005). 
10. Rangel-Moreno, J. et al. Inducible bronchus-associated lymphoid tissue (iBALT) in patients with pulmonary complications of rheumatoid arthritis. J Clin Invest 116, 3183-94 (2006).

11. Thurlings, R.M. et al. Synovial tissue response to rituximab: mechanism of action and identification of biomarkers of response. Ann Rheum Dis 67, 917-25 (2008).

12. Thurlings, R.M. et al. Synovial lymphoid neogenesis does not define a specific clinical rheumatoid arthritis phenotype. Arthritis Rheum 58, 1582-9 (2008).

13. Vos, K. et al. Early effects of rituximab on the synovial cell infiltrate in patients with rheumatoid arthritis. Arthritis Rheum 56, 772-8 (2007).

14. Yanni, G., Whelan, A., Feighery, C. \& Bresnihan, B. Analysis of cell populations in rheumatoid arthritis synovial tissues. Semin Arthritis Rheum 21, 393-9 (1992).

15. Manzo, A., Bombardieri, M., Humby, F. \& Pitzalis, C. Secondary and ectopic lymphoid tissue responses in rheumatoid arthritis: from inflammation to autoimmunity and tissue damage/remodeling. Immunol Rev 233, 267-85 (2010).

16. Aziz, K.E., McCluskey, P.J. \& Wakefield, D. Characterisation of follicular dendritic cells in labial salivary glands of patients with primary Sjogren syndrome: comparison with tonsillar lymphoid follicles. Ann Rheum Dis 56, 140-3 (1997).

17. Barone, F. et al. Association of CXCL13 and CCL21 expression with the progressive organization of lymphoid-like structures in Sjogren's syndrome. Arthritis Rheum 52, 1773-84 (2005).

18. Croia, C. et al. Implication of Epstein-Barr virus infection in disease-specific autoreactive B cell activation in ectopic lymphoid structures of Sjogren's syndrome. Arthritis Rheumatol 66, 2545-57 (2014).

19. Jonsson, M.V., Skarstein, K., Jonsson, R. \& Brun, J.G. Serological implications of germinal center-like structures in primary Sjogren's syndrome. J Rheumatol 34, 2044-9 (2007).

20. Stott, D.I., Hiepe, F., Hummel, M., Steinhauser, G. \& Berek, C. Antigen-driven clonal proliferation of $B$ cells within the target tissue of an autoimmune disease. The salivary glands of patients with Sjogren's syndrome. J Clin Invest 102, 938-46 (1998).

21. Theander, E. et al. Lymphoid organisation in labial salivary gland biopsies is a possible predictor for the development of malignant lymphoma in primary Sjogren's syndrome. Ann Rheum Dis 70, 1363-8 (2011).

22. Pijpe, J. et al. Parotid gland biopsy compared with labial biopsy in the diagnosis of patients with primary Sjogren's syndrome. Rheumatology (Oxford) 46, 335-41 (2007).

23. Bombardieri, M. et al. Activation-induced cytidine deaminase expression in follicular dendritic cell networks and interfollicular large B cells supports functionality of ectopic lymphoid neogenesis in autoimmune sialoadenitis and MALT lymphoma in Sjogren's syndrome. J Immunol 179, 4929-38 (2007).

24. Chang, A. et al. In situ B cell-mediated immune responses and tubulointerstitial inflammation in human lupus nephritis. J Immunol 186, 1849-60 (2011).

25. Shen, Y. et al. Association of intrarenal B-cell infiltrates with clinical outcome in lupus nephritis: a study of 192 cases. Clin Dev Immunol 2012, 967584 (2012).

26. Neusser, M.A. et al. Intrarenal production of B-cell survival factors in human lupus nephritis. Mod Pathol 24, 98-107 (2011).

27. Liu, Z. et al. Interferon-alpha accelerates murine systemic lupus erythematosus in a T celldependent manner. Arthritis Rheum 63, 219-29 (2011).

28. Mathian, A., Gallegos, M., Pascual, V., Banchereau, J. \& Koutouzov, S. Interferon-alpha induces unabated production of short-lived plasma cells in pre-autoimmune lupus-prone (NZBXNZW)F1 mice but not in BALB/c mice. Eur J Immunol 41, 863-72 (2011).

29. Mahevas, M. et al. B cell depletion in immune thrombocytopenia reveals splenic long-lived plasma cells. J Clin Invest 123, 432-42 (2013).

30. Domeier, P.P. et al. IFN-gamma receptor and STAT1 signaling in B cells are central to spontaneous germinal center formation and autoimmunity. J Exp Med 213, 715-32 (2016). 
31. Jackson, S.W. et al. B cell IFN-gamma receptor signaling promotes autoimmune germinal centers via cell-intrinsic induction of BCL-6. J Exp Med 213, 733-50 (2016).

32. Arahata, K. \& Engel, A.G. Monoclonal antibody analysis of mononuclear cells in myopathies. I: Quantitation of subsets according to diagnosis and sites of accumulation and demonstration and counts of muscle fibers invaded by T cells. Ann Neurol 16, 193-208 (1984).

33. De Bleecker, J.L., Engel, A.G. \& Butcher, E.C. Peripheral lymphoid tissue-like adhesion molecule expression in nodular infiltrates in inflammatory myopathies. Neuromuscul Disord 6, 255-60 (1996).

34. Lopez De Padilla, C.M., Vallejo, A.N., Lacomis, D., McNallan, K. \& Reed, A.M. Extranodal lymphoid microstructures in inflamed muscle and disease severity of new-onset juvenile dermatomyositis. Arthritis Rheum 60, 1160-72 (2009).

35. Salajegheh, M. et al. Permissive environment for B-cell maturation in myositis muscle in the absence of B-cell follicles. Muscle Nerve 42, 576-83 (2010).

36. Bradshaw, E.M. et al. A local antigen-driven humoral response is present in the inflammatory myopathies. J Immunol 178, 547-56 (2007).

37. Drayton, D.L., Liao, S., Mounzer, R.H. \& Ruddle, N.H. Lymphoid organ development: from ontogeny to neogenesis. Nat Immunol 7, 344-53 (2006).

38. Jones, G.W. et al. Interleukin-27 inhibits ectopic lymphoid-like structure development in early inflammatory arthritis. J Exp Med 212, 1793-802 (2015).

39. Mebius, R.E. Organogenesis of lymphoid tissues. Nat Rev Immunol 3, 292-303 (2003).

40. van de Pavert, S.A. \& Mebius, R.E. New insights into the development of lymphoid tissues. Nat Rev Immunol 10, 664-74 (2010).

41. Randall, T.D. \& Mebius, R.E. The development and function of mucosal lymphoid tissues: a balancing act with micro-organisms. Mucosal Immunol 7, 455-66 (2014).

42. Browning, J.L. et al. Lymphotoxin-beta receptor signaling is required for the homeostatic control of HEV differentiation and function. Immunity 23, 539-50 (2005).

43. Bugatti, S. et al. High expression levels of the B cell chemoattractant CXCL13 in rheumatoid synovium are a marker of severe disease. Rheumatology (Oxford) 53, 1886-95 (2014).

44. Salomonsson, $\mathrm{S}$. et al. Cellular basis of ectopic germinal center formation and autoantibody production in the target organ of patients with Sjogren's syndrome. Arthritis Rheum 48, 3187-201 (2003).

45. Weyand, C.M. \& Goronzy, J.J. Ectopic germinal center formation in rheumatoid synovitis. Ann N Y Acad Sci 987, 140-9 (2003).

46. Link, A. et al. Fibroblastic reticular cells in lymph nodes regulate the homeostasis of naive $T$ cells. Nat Immunol 8, 1255-65 (2007).

47. Manzo, A. et al. CCL21 expression pattern of human secondary lymphoid organ stroma is conserved in inflammatory lesions with lymphoid neogenesis. Am J Pathol 171, 1549-62 (2007).

48. Barone, F. et al. CXCL13, CCL21, and CXCL12 expression in salivary glands of patients with Sjogren's syndrome and MALT lymphoma: association with reactive and malignant areas of lymphoid organization. J Immunol 180, 5130-40 (2008).

49. Carlsen, H.S., Baekkevold, E.S., Morton, H.C., Haraldsen, G. \& Brandtzaeg, P. Monocyte-like and mature macrophages produce $\mathrm{CXCL13}$ (B cell-attracting chemokine 1 ) in inflammatory lesions with lymphoid neogenesis. Blood 104, 3021-7 (2004).

50. Kobayashi, $\mathrm{S}$. et al. A distinct human CD4+ T cell subset that secretes CXCL13 in rheumatoid synovium. Arthritis Rheum 65, 3063-72 (2013).

51. Manzo, A. et al. Mature antigen-experienced T helper cells synthesize and secrete the $B$ cell chemoattractant CXCL13 in the inflammatory environment of the rheumatoid joint. Arthritis Rheum 58, 3377-87 (2008). 
52. GeurtsvanKessel, C.H. et al. Dendritic cells are crucial for maintenance of tertiary lymphoid structures in the lung of influenza virus-infected mice. J Exp Med 206, 2339-49 (2009).

53. Amft, N. et al. Ectopic expression of the B cell-attracting chemokine BCA-1 (CXCL13) on endothelial cells and within lymphoid follicles contributes to the establishment of germinal center-like structures in Sjogren's syndrome. Arthritis Rheum 44, 2633-41 (2001).

54. Xanthou, G. et al. "Lymphoid" chemokine messenger RNA expression by epithelial cells in the chronic inflammatory lesion of the salivary glands of Sjogren's syndrome patients: possible participation in lymphoid structure formation. Arthritis Rheum 44, 408-18 (2001).

55. Peters, A. et al. Th17 cells induce ectopic lymphoid follicles in central nervous system tissue inflammation. Immunity 35, 986-96 (2011).

56. Rangel-Moreno, J. et al. The development of inducible bronchus-associated lymphoid tissue depends on IL-17. Nat Immunol 12, 639-46 (2011).

57. Sawa, S. et al. Lineage relationship analysis of RORgammat+ innate lymphoid cells. Science 330, 665-9 (2010).

58. Chabaud, M. et al. Human interleukin-17: A T cell-derived proinflammatory cytokine produced by the rheumatoid synovium. Arthritis Rheum 42, 963-70 (1999).

59. Canete, J.D. et al. Ectopic lymphoid neogenesis is strongly associated with activation of the IL-23 pathway in rheumatoid synovitis. Arthritis Res Ther 17, 173 (2015).

60. Dudakov, J.A., Hanash, A.M. \& van den Brink, M.R. Interleukin-22: immunobiology and pathology. Annu Rev Immunol 33, 747-85 (2015).

61. Barone, F. et al. IL-22 regulates lymphoid chemokine production and assembly of tertiary lymphoid organs. Proc Natl Acad Sci U S A 112, 11024-9 (2015).

62. Bombardieri, M. et al. Inducible tertiary lymphoid structures, autoimmunity, and exocrine dysfunction in a novel model of salivary gland inflammation in C57BL/6 mice. J Immunol 189, 3767-76 (2012).

63. Ciccia, F. et al. Potential involvement of IL-22 and IL-22-producing cells in the inflamed salivary glands of patients with Sjogren's syndrome. Ann Rheum Dis 71, 295-301 (2012).

64. Slight, S.R. et al. CXCR5(+) T helper cells mediate protective immunity against tuberculosis. J Clin Invest 123, 712-26 (2013).

65. Shulman, Z. et al. Dynamic signaling by $T$ follicular helper cells during germinal center $B$ cell selection. Science 345, 1058-62 (2014).

66. Breitfeld, D. et al. Follicular B helper T cells express CXC chemokine receptor 5 , localize to B cell follicles, and support immunoglobulin production. J Exp Med 192, 1545-52 (2000).

67. Karnell, J.L. \& Ettinger, R. The interplay of IL-21 and BAFF in the formation and maintenance of human B cell memory. Frontiers in Immunology 3 (2012).

68. Liu, D. et al. T-B-cell entanglement and ICOSL-driven feed-forward regulation of germinal centre reaction. Nature 517, 214-8 (2015).

69. Jungel, A. et al. Expression of interleukin-21 receptor, but not interleukin-21, in synovial fibroblasts and synovial macrophages of patients with rheumatoid arthritis. Arthritis Rheum 50, 1468-76 (2004).

70. Kwok, S.K. et al. Interleukin-21 promotes osteoclastogenesis in humans with rheumatoid arthritis and in mice with collagen-induced arthritis. Arthritis Rheum 64, 740-51 (2012).

71. Young, D.A. et al. Blockade of the interleukin-21/interleukin-21 receptor pathway ameliorates disease in animal models of rheumatoid arthritis. Arthritis Rheum 56, 1152-63 (2007).

72. Liu, H., Liu, G., Gong, L., Zhang, Y. \& Jiang, G. Local suppression of IL-21 in submandibular glands retards the development of Sjogren's syndrome in non-obese diabetic mice. J Oral Pathol Med 41, 728-35 (2012).

73. Gong, Y.Z. et al. Differentiation of follicular helper T cells by salivary gland epithelial cells in primary Sjogren's syndrome. J Autoimmun 51, 57-66 (2014). 
74. $\quad$ Stumhofer, J.S. et al. Interleukin 27 negatively regulates the development of interleukin 17producing $T$ helper cells during chronic inflammation of the central nervous system. Nat Immunol 7, 937-45 (2006).

75. Lee, B.H., Carcamo, W.C., Chiorini, J.A., Peck, A.B. \& Nguyen, C.Q. Gene therapy using IL-27 ameliorates Sjogren's syndrome-like autoimmune exocrinopathy. Arthritis Res Ther 14, R172 (2012).

76. Batten, M. et al. IL-27 supports germinal center function by enhancing IL-21 production and the function of T follicular helper cells. J Exp Med 207, 2895-906 (2010).

77. Sage, P.T. \& Sharpe, A.H. T follicular regulatory cells in the regulation of B cell responses. Trends Immunol 36, 410-8 (2015).

78. Corsiero, E. et al. Single cell cloning and recombinant monoclonal antibodies generation from RA synovial B cells reveal frequent targeting of citrullinated histones of NETs. Ann Rheum Dis (2015).

79. Scheel, T., Gursche, A., Zacher, J., Haupl, T. \& Berek, C. V-region gene analysis of locally defined synovial $B$ and plasma cells reveals selected $B$ cell expansion and accumulation of plasma cell clones in rheumatoid arthritis. Arthritis Rheum 63, 63-72 (2011).

80. Bombardieri, M. et al. A BAFF/APRIL-dependent TLR3-stimulated pathway enhances the capacity of rheumatoid synovial fibroblasts to induce AID expression and Ig class-switching in B cells. Annals of the Rheumatic Diseases 70, 1857-1865 (2011).

81. Le Pottier, L. et al. Ectopic germinal centers are rare in Sjogren's syndrome salivary glands and do not exclude autoreactive B cells. J Immunol 182, 3540-7 (2009).

82. Canete, J.D. et al. Ectopic lymphoid neogenesis in psoriatic arthritis. Ann Rheum Dis 66, 7206 (2007).

83. Cantaert, T. et al. B lymphocyte autoimmunity in rheumatoid synovitis is independent of ectopic lymphoid neogenesis. J Immunol 181, 785-94 (2008).

84. Canete, J.D. et al. Clinical significance of synovial lymphoid neogenesis and its reversal after anti-tumour necrosis factor alpha therapy in rheumatoid arthritis. Ann Rheum Dis 68, 751-6 (2009).

85. Rosengren, S. et al. Elevated autoantibody content in rheumatoid arthritis synovia with lymphoid aggregates and the effect of rituximab. Arthritis Res Ther 10, R105 (2008).

86. Amara, K. et al. Monoclonal IgG antibodies generated from joint-derived $B$ cells of RA patients have a strong bias toward citrullinated autoantigen recognition. J Exp Med 210, 445-55 (2013).

87. Risselada, A.P., Looije, M.F., Kruize, A.A., Bijlsma, J.W. \& van Roon, J.A. The role of ectopic germinal centers in the immunopathology of primary Sjogren's syndrome: a systematic review. Semin Arthritis Rheum 42, 368-76 (2013).

88. Croia, C. et al. Epstein-Barr virus persistence and infection of autoreactive plasma cells in synovial lymphoid structures in rheumatoid arthritis. Ann Rheum Dis 72, 1559-68 (2013).

89. Doorenspleet, M.E. et al. Rheumatoid arthritis synovial tissue harbours dominant B-cell and plasma-cell clones associated with autoreactivity. Ann Rheum Dis 73, 756-62 (2014).

90. Klarenbeek, P.L. et al. Inflamed target tissue provides a specific niche for highly expanded Tcell clones in early human autoimmune disease. Ann Rheum Dis 71, 1088-93 (2012).

91. Nutt, S.L., Hodgkin, P.D., Tarlinton, D.M. \& Corcoran, L.M. The generation of antibodysecreting plasma cells. Nat Rev Immunol 15, 160-71 (2015).

92. Szyszko, E.A. et al. Salivary glands of primary Sjogren's syndrome patients express factors vital for plasma cell survival. Arthritis Res Ther 13, R2 (2011).

93. Kim, K.W. et al. Up-regulation of stromal cell-derived factor 1 (CXCL12) production in rheumatoid synovial fibroblasts through interactions with T lymphocytes: role of interleukin17 and CD40L-CD40 interaction. Arthritis Rheum 56, 1076-86 (2007). 
94. Noss, E.H., Nguyen, H.N., Chang, S.K., Watts, G.F. \& Brenner, M.B. Genetic polymorphism directs IL-6 expression in fibroblasts but not selected other cell types. Proc Natl Acad Sci U S A 112, 14948-53 (2015).

95. $\mathrm{Xu}, \mathrm{X}$. et al. Increased expression of activation-induced cytidine deaminase is associated with anti-CCP and rheumatoid factor in rheumatoid arthritis. Scand J Immunol 70, 309-16 (2009).

96. Lanfant-Weybel, $K$. et al. Synovium CD20 expression is a potential new predictor of bone erosion progression in very-early arthritis treated by sequential DMARDs monotherapy -- a pilot study from the VErA cohort. Joint Bone Spine 79, 574-80 (2012).

97. van de Sande, M.G. et al. Presence of lymphocyte aggregates in the synovium of patients with early arthritis in relationship to diagnosis and outcome: is it a constant feature over time? Ann Rheum Dis 70, 700-3 (2011).

98. Royer, B. et al. Lymphomas in patients with Sjogren's syndrome are marginal zone B-cell neoplasms, arise in diverse extranodal and nodal sites, and are not associated with viruses. Blood 90, 766-75 (1997).

99. Bende, R.J. et al. Among B cell non-Hodgkin's lymphomas, MALT lymphomas express a unique antibody repertoire with frequent rheumatoid factor reactivity. J Exp Med 201, 122941 (2005).

100. Martin, T. et al. Salivary gland lymphomas in patients with Sjogren's syndrome may frequently develop from rheumatoid factor B cells. Arthritis Rheum 43, 908-16 (2000).

101. Gasparotto, D. et al. Extrasalivary lymphoma development in Sjogren's syndrome: clonal evolution from parotid gland lymphoproliferation and role of local triggering. Arthritis Rheum 48, 3181-6 (2003).

102. Espeli, M. et al. Local renal autoantibody production in lupus nephritis. J Am Soc Nephrol 22, 296-305 (2011).

103. Klaasen, R. et al. The relationship between synovial lymphocyte aggregates and the clinical response to infliximab in rheumatoid arthritis: a prospective study. Arthritis Rheum 60, 321724 (2009).

104. Kavanaugh, A. et al. Assessment of rituximab's immunomodulatory synovial effects (ARISE trial). 1: clinical and synovial biomarker results. Ann Rheum Dis 67, 402-8 (2008).

105. Delli, K. et al. Towards personalised treatment in primary Sjogren's syndrome: baseline parotid histopathology predicts responsiveness to rituximab treatment. Ann Rheum Dis (2016).

106. Hamza, N. et al. Persistence of immunoglobulin-producing cells in parotid salivary glands of patients with primary Sjogren's syndrome after B cell depletion therapy. Ann Rheum Dis 71, 1881-7 (2012).

107. Pijpe, J. et al. Clinical and histologic evidence of salivary gland restoration supports the efficacy of rituximab treatment in Sjogren's syndrome. Arthritis Rheum 60, 3251-6 (2009).

108. Quartuccio, L. et al. Resistance to rituximab therapy and local BAFF overexpression in Sjogren's syndrome-related myoepithelial sialadenitis and low-grade parotid B-cell lymphoma. Open Rheumatol J 2, 38-43 (2008).

109. Teng, Y.K., Levarht, E.W., Toes, R.E., Huizinga, T.W. \& van Laar, J.M. Residual inflammation after rituximab treatment is associated with sustained synovial plasma cell infiltration and enhanced B cell repopulation. Ann Rheum Dis 68, 1011-6 (2009).

110. Rosengren, S., Wei, N., Kalunian, K.C., Kavanaugh, A. \& Boyle, D.L. CXCL13: a novel biomarker of B-cell return following rituximab treatment and synovitis in patients with rheumatoid arthritis. Rheumatology (Oxford) 50, 603-10 (2011).

111. Buch, M.H. et al. The value of synovial cytokine expression in predicting the clinical response to TNF antagonist therapy (infliximab). Rheumatology (Oxford) 47, 1469-75 (2008).

112. Das, S. et al. Abatacept or tocilizumab after rituximab in rheumatoid arthritis? An exploratory study suggests non-response to rituximab is associated with persistently high IL6 and better clinical response to IL-6 blocking therapy. Ann Rheum Dis 73, 909-12 (2014). 
113. Adler, S. et al. Evaluation of histologic, serologic, and clinical changes in response to abatacept treatment of primary Sjogren's syndrome: a pilot study. Arthritis Care Res (Hoboken) 65, 1862-8 (2013).

114. Fava, R.A. et al. A role for the lymphotoxin/LIGHT axis in the pathogenesis of murine collagen-induced arthritis. J Immunol 171, 115-26 (2003).

115. Gatumu, M.K. et al. Blockade of lymphotoxin-beta receptor signaling reduces aspects of Sjogren's syndrome in salivary glands of non-obese diabetic mice. Arthritis Res Ther 11, R24 (2009).

116. St.Clair, EW. et al. The Clinical Efficacy and Safety of Baminercept, a Lymphotoxin-Beta Receptor Fusion Protein, in Primary Sjögren's Syndrome: Results from a Randomized, Double-Blind, Placebo-Controlled Phase II Trial (Abstract). Arthritis Rheumatol 67, Suppl 10 (2015).

117. Hu, Y.L., Metz, D.P., Chung, J., Siu, G. \& Zhang, M. B7RP-1 blockade ameliorates autoimmunity through regulation of follicular helper T cells. J Immunol 182, 1421-8 (2009).

118. Alzabin, S. et al. Incomplete response of inflammatory arthritis to TNF alpha blockade is associated with the Th17 pathway. Annals of the Rheumatic Diseases 71, 1741-1748 (2012).

119. Ferrari, M., Onuoha, S.C. \& Pitzalis, C. Trojan horses and guided missiles: targeted therapies in the war on arthritis. Nat Rev Rheumatol 11, 328-37 (2015).

\section{Author contributions}

M.B. and M.J.L. researched data for the article. All authors made a substantial contribution to discussion of the content, and writing, reviewing and editing the manuscript before submission.

\section{Competing interests statement}

The authors declare that they have no competing interests.

\section{Review criteria}

We searched PubMed for English-language, full-text original research and review articles published in peer-reviewed international journals. Search terms used included "ectopic lymphoid structures", "tertiary lymphoid organs", "lymphoid neogenesis", 
"ectopic germinal centres", "rheumatic autoimmune diseases", "rheumatoid arthritis", "seronegative spondyloarthritis", "psoriatic arthritis", "Sjogren's syndrome", "SLE" and "polymyositis or dermatomyositis". The reference lists of identified papers were searched for further leads.

\section{Key points}

- Ectopic lymphoid structures (ELSs) develop in the target organs of a subset of patients with rheumatic autoimmune diseases and recapitulate key cellular and molecular features normally present in secondary lymphoid organs

- ELSs in rheumatic autoimmune diseases can function as germinal centres, favouring B-cell selection and plasma-cell differentiation

- B cells and plasma cells associated with ELSs in rheumatic autoimmune diseases frequently display an autoreactive phenotype towards disease-specific autoantigens

- Ectopic germinal centres in patients with Sjögren syndrome have been associated with more severe systemic manifestations and a higher risk of B-cell lymphoma

- In rheumatoid arthritis, emerging but as-yet-inconclusive evidence suggests a role for ELSs in influencing disease evolution and the response to conventional and biologic treatments

- Several candidate therapeutic agents that target ELS-associated pathways are currently in clinical trials for rheumatic autoimmune diseases 
Figure 1: Ectopic lymphoid structures that form in rheumatic autoimmune diseases share features of secondary lymphoid organs. Ectopic lymphoid structures (ELSs) form around the intercalated ducts in the salivary glands of patients with Sjögren syndrome. a| Schematic representation of ELSs showing the full acquisition of features of secondary lymphoid organs: segregation of $\mathrm{T}$ cells and B cells into separate areas; development of high endothelial venules (HEVs) at the periphery of the lymphoid aggregates in the T-cell-rich areas; differentiation of networks of follicular dendritic cells (FDCs) that support a functional germinal centre response; and differentiation of hypermutated and class-switched plasma cells, which typically acquire a perifollicular localization with frequent infiltration of epithelial cells (ECs) from the ducts and acini. b| Immunohistochemical staining for CD3 (T cells), CD20 (B cells), CD21 (FDCs) and CD138 (plasma cells) illustrates cellular localization within ELSs arising in the salivary glands of Sjögren's syndrome. Original magnification x100 for CD3, CD20, CD21 and CD138.

Figure 2: Schematic representation illustrating the journey of $\mathrm{T}$ follicular helper $\left(\mathrm{T}_{\mathrm{FH}}\right)$ cells from the T-cell-rich area of the ELS to the B-cell follicles where $\mathrm{T}_{\mathrm{FH}}$ cells initiate and sustain germinal centre responses.

a| From left to right. Gradients of lymphoid chemokines CC-chemokine ligand 19 (CCL19), CCL21 and CXC-chemokine ligand 13 (CXCL13) regulate the organization of T cells and B cells, respectively, into discrete areas, as well as the migration of specialized $\mathrm{T}_{\mathrm{FH}}$ cells into B-cell follicles to support B cells. Briefly, in the context of high levels of CCL19 and CCL21 around HEVs in the T-cell-rich area of the ELS mature CCR7 ${ }^{+}$CD62 $\mathrm{L}^{+}$ antigen-presenting cells (APC) form cognate interactions with $\mathrm{CCR} 7{ }^{+} \mathrm{CD} 62 \mathrm{~L}^{+} \mathrm{CD} 4{ }^{+} \mathrm{T}$ cells 
(i.e. central memory and naive $\mathrm{T}$ cells) leading to T-cell activation. In the presence of cytokines released in the local microenvironment, $\mathrm{T}_{\mathrm{FH}}$ cells downregulate CC-chemokine receptor 7 (CCR7) and upregulate inducible T-cell co-stimulator (ICOS) and CXCchemokine receptor 5 (CXCR5), the latter allowing $\mathrm{T}_{\mathrm{FH}}$ cells to migrate into $\mathrm{B}$ cell follicles in response to CXCL13 gradients. At the border and within ectopic germinal centres, $\mathrm{T}_{\mathrm{FH}}$ cells form cognate interactions with $\mathrm{B}$ cells and, in the context of costimulation from ICOS ligand (ICOSL) expressed by B cells, release high amount of the $\mathrm{T}_{\mathrm{FH}}$ cell signature cytokine, IL-21. In turn, IL-21 (in synergy with other cytokines) induces the differentiation of germinal centre B cells by upregulating B cell lymphoma 6 (BCL6) and leading to the de novo expression of activation-induced cytidine deaminase (AID), which is required for somatic hypermutation of the immunoglobulin genes followed by isotype class-switch recombination. B cells that acquire a higher affinity towards the antigen following somatic hypermutation receive strong survival and proliferative signals within the germinal centre and differentiate into high-affinity plasma cells (and memory B cells). Perifollicular plasma cells leaving ectopic germinal centres receive strong migratory and survival signals in the form of CXCL12 and a proliferation-inducing ligand (APRIL), causing the retention of long lived plasma cells in the tissue.

b| Confocal multicolour immunofluorescence microscopy depicts $\mathrm{T}_{\mathrm{FH}}$ cells localizing within ectopic B cell follicles in ELS forming in the parotid glands of patients with Sjögren syndrome. $\mathrm{T}_{\mathrm{FH}}$ cells are identified as $\mathrm{ICOS}^{+}$(depicted in blue) $\mathrm{T}$ cells that form close cell-cell contact with $\mathrm{CD}^{2} 0^{+}$(red) in B cell follicles both in the mantle zone and, within ectopic germinal centres, with BCL6 (green) germinal centre B cells. Original magnification: $\times 200$ for CD20, ICOS and BCL6. 
Figure 3: Ectopic germinal centres sustain antigen-specific and disease-specific autoimmune responses.

Ectopic lymphoid structures (ELSs) arising in the salivary glands of Sjögren syndrome (part a) and in the synovium of rheumatoid arthritis (RA; part b) are depicted. Although ELSs in RA and Sjögren syndrome display overlapping architecture and are regulated by similar mechanisms, they favour the affinity maturation and differentiation of plasma cells reactive against disease-specific autoantigens. These autoantigens are exposed as a result of the chronic inflammatory process and can be presented by both professional antigen-presenting cells (APC) and B cells to T cells.

Left side, representative schematic of the potential source of autoantigens driving the formation of ELS. Briefly, in Sjögren's syndrome (part a), after an initial unknown trigger (i.e. viral infection), necrotic/apoptotic epithelial cells release autoantigens. In the RA synovium (part b, bottom half), breach of self-tolerance to citrullinated antigens precedes the onset of ELS. Circulating ACPA (i.e. as immune complexes, IC) may enter the RA synovium due to increased vascular permeabilization (i.e. injury/infection etc). Once inflammation is established, citrullinated antigens can be locally released by several cell types, including neutrophil extracellular traps, NET.

Right side, double immunofluorescence microscopy demonstrating that perifollicular CD138+ plasma cells (PCs, depicted in green) in Sjögren syndrome salivary glands (part a, top half) react against the Sjögren syndrome-associated autoantigen Ro52 (stained in red) but not against Cit-fibrinogen; conversely, CD138+ plasma cells in the RA synovium (part b, bottom half) display strong reactivity to Cit-fibrinogen (in red), but not Ro52.

Original magnification: $\times 40$ for CD20 (left side) and $\times 400$ for CD138/Ro52 and CD138/Cit-Fib (right side). 
Table 1 | Comparison of the main cellular sources of the key factors regulating ectopic versus embryonic lymphoid organogenesis

\begin{tabular}{|c|c|c|c|}
\hline Pathway & Lymphoid organogenesis & $\begin{array}{l}\text { Initiation and } \\
\text { progression of ELS } \\
\text { (animal models) }\end{array}$ & $\begin{array}{l}\text { ELS-positive target tissues in human } \\
\text { rheumatic autoimmune diseases }\end{array}$ \\
\hline LT $\beta$ & $\begin{array}{c}\text { LTi } \\
\text { LTin } \\
\text { B cells (neonatal spleen) }\end{array}$ & $\begin{array}{c}\mathrm{CD}_{11 \mathrm{~b}^{+} \mathrm{CD} 11 \mathrm{c}^{+} \mathrm{DCs}} \\
\mathrm{CD}^{+} \alpha \beta \text { T cells } \\
\text { B cells }\end{array}$ & $\begin{array}{c}\text { B cells } \\
\text { CD } 4^{+} \text {T cells }\end{array}$ \\
\hline CXCL13 & LTo & $\begin{array}{l}\text { CD } 11 b^{+} \text {CD } 11 c^{+} \text {DCs } \\
\text { GP38 }{ }^{+} \text {stromal cells }\end{array}$ & $\begin{array}{c}\text { CD4 }{ }^{+} \text {T cells } \\
\text { CD14 }{ }^{+} \text {monocytes } \\
\text { CD68 }{ }^{+} \text {macrophages or DCs } \\
\text { Endothelial cells } \\
\text { Epithelial cells } \\
\text { Fibroblast-like synoviocytes } \\
\text { Follicular DCs }\end{array}$ \\
\hline CCL19 & LTo & $\begin{array}{l}\text { CD11b+CD11c } \mathrm{c}^{+} \mathrm{DCs} \\
\text { Stromal cells }\end{array}$ & Myofibroblast-like stroma \\
\hline CCL21 & LTo & $\begin{array}{l}\text { CD11 } \mathrm{b}^{+} \mathrm{CD} 11 \mathrm{c}^{+} \mathrm{DCs} \\
\text { Stromal cells }\end{array}$ & $\begin{array}{c}\text { Myofibroblast-like stroma } \\
\text { Lymphatic endothelial cells } \\
\text { DCs }\end{array}$ \\
\hline RANKL & LTo & Stromal cells & $\begin{array}{c}\text { B cells } \\
\text { Fibroblast-like synoviocytes }\end{array}$ \\
\hline IL-7 & LTo & Stromal cells & $\begin{array}{c}\text { Fibroblast-like synoviocytes } \\
\text { Sublining synovial macrophages }\end{array}$ \\
\hline IL-17 & ND & $\begin{array}{c}\text { ILC3 } \\
\mathrm{CD}^{+} \gamma \delta \text { T cells } \\
\text { CD4+ } \alpha \beta \text { T cells }\end{array}$ & $\begin{array}{l}\text { CD4+ }{ }^{+} \text {T cells } \\
\text { Mast cells }\end{array}$ \\
\hline IL-22 & ND & $\begin{array}{c}\text { ILC3 } \\
\text { CD4 }{ }^{+} \gamma \delta \text { T cells } \\
\text { CD4+ } \alpha \beta \text { T cells }\end{array}$ & $\begin{array}{c}\text { CD4+ }{ }^{+} \text {T cells } \\
\text { NKp44+ NK cells }\end{array}$ \\
\hline
\end{tabular}

Abbreviations: CCL, CC-chemokine ligand; CXCL, CXC-chemokine ligand; DCs, dendritic cells; ELS, ectopic lymphoid structure; FCRL4, Fc receptor-like protein 4; ILC3, type 3 innate lymphoid cells; NK cell, natural killer cell; LT $\beta$, lymphotoxin- $\beta$; LTi, lymphoid tissue inducer cells; LTin, lymphoid tissue initiator cells; LTo, mesenchymal organizer cells; ND, not determined; RANKL, RANK ligand. 
Table 2: Randomized clinical trials in rheumatic autoimmune diseases of developmental drugs targeting pathways involved in ectopic lymphoid cell formation and function.

\begin{tabular}{|c|c|c|c|c|c|c|}
\hline \multirow[t]{2}{*}{$\begin{array}{l}\text { Pathway } \\
\text { inhibited }\end{array}$} & \multirow[t]{2}{*}{ Compound } & \multirow[t]{2}{*}{ Class of drug } & \multicolumn{4}{|c|}{$\begin{array}{l}\text { Completed and ongoing clinical trials in ELS-positive } \\
\text { rheumatic autoimmune diseases }\end{array}$} \\
\hline & & & \begin{tabular}{|l} 
Disease \\
\end{tabular} & $\begin{array}{l}\text { Phase } \\
\text { of trial }\end{array}$ & Trial status & Trial ID \\
\hline \multirow[t]{5}{*}{ IL-17 } & Secukinumab & $\begin{array}{l}\text { IL-17A-specific } \\
\text { monoclonal antibody }\end{array}$ & RA & III & Recruiting & $\begin{array}{l}\text { NCT01377012 } \\
\text { NCT01350804 }\end{array}$ \\
\hline & Ixekizumab & $\begin{array}{l}\text { IL-17A-specific } \\
\text { monoclonal antibody }\end{array}$ & RA & II & Completed & NCT00966875 \\
\hline & Brodalumab & $\begin{array}{l}\text { IL-17RA-specific } \\
\text { monoclonal antibody }\end{array}$ & RA & II & Completed & NCT00950989 \\
\hline & ABT-122 & $\begin{array}{l}\text { TNF and IL-17 } \\
\text { bispecific antibody }\end{array}$ & RA & $\mathrm{I}$ & Ongoing & NCT01853033 \\
\hline & CNTO-6785 & $\begin{array}{l}\text { IL-17A-specific } \\
\text { monoclonal antibody }\end{array}$ & RA & III & Recruiting & NCT01909427 \\
\hline \multirow[t]{3}{*}{ IL-21 } & \multirow[t]{2}{*}{ NNC0114-0006 } & \multirow{2}{*}{$\begin{array}{l}\text { IL-21-specific } \\
\text { monoclonal antibody }\end{array}$} & RA & II & Completed & NCT01647451 \\
\hline & & & SLE & I & Completed & NCT 01689025 \\
\hline & NNC0114-0005 & $\begin{array}{l}\text { IL-21-specific } \\
\text { monoclonal antibody }\end{array}$ & RA & I & Completed & NCT01208506 \\
\hline \multirow{3}{*}{$\begin{array}{l}\text { LT } \alpha \text { or } \\
\text { LT } \beta\end{array}$} & \multirow{2}{*}{ Baminercept- $\alpha$} & \multirow{2}{*}{$\begin{array}{l}\text { LT } \beta \text { R-immunoglobulin } \\
\text { fusion protein }\end{array}$} & RA & II & Completed & NCT00664573 \\
\hline & & & SS & II & Recruiting & NCT01552681 \\
\hline & Pateclizumab & $\begin{array}{l}\text { Anti-LT } \alpha \text { monoclonal } \\
\text { antibody }\end{array}$ & RA & II & Completed & NCT01225393 \\
\hline RANKL & Denosumab & $\begin{array}{l}\text { RANKL-specific } \\
\text { monoclonal antibody }\end{array}$ & RA & III & Ongoing & NCT01973569 \\
\hline \multirow[t]{2}{*}{$\begin{array}{l}\text { ICOS- } \\
\text { ICOSL }\end{array}$} & \multirow[t]{2}{*}{ AMG557/MEDI5872 } & \multirow{2}{*}{$\begin{array}{l}\text { ICOSL-specific } \\
\text { monoclonal antibody }\end{array}$} & SLE & I & Recruiting & NCT01683695 \\
\hline & & & SS & II & Recruiting & NCT02334306 \\
\hline \multirow{2}{*}{$\begin{array}{l}\text { CD40- } \\
\text { CD40L }\end{array}$} & \multirow[t]{2}{*}{ CFZ533 } & \multirow{2}{*}{$\begin{array}{l}\text { CD40-specific } \\
\text { monoclonal antibody }\end{array}$} & SS & II & Recruiting & NCT02291029 \\
\hline & & & RA & $\mathrm{I}$ & Recruiting & NCT02089087 \\
\hline \multirow[t]{4}{*}{ BAFF } & Belimumab & $\begin{array}{l}\text { BAFF-specific } \\
\text { monoclonal antibody }\end{array}$ & SS & II & Completed & $\begin{array}{l}\text { NCT01008982 (SS, } \\
\text { phase II, completed) }\end{array}$ \\
\hline & $\begin{array}{l}\text { Belimumab and } \\
\text { rituximab }\end{array}$ & $\begin{array}{l}\text { Combination of BAFF- } \\
\text { specific and CD20- } \\
\text { specific monoclonal } \\
\text { antibody }\end{array}$ & SS & II & Recruiting & $\begin{array}{l}\text { NCT02631538 (SS, } \\
\text { phase II, recruiting) }\end{array}$ \\
\hline & \multirow[t]{2}{*}{ Tabalumab } & \multirow[t]{2}{*}{$\begin{array}{l}\text { BAFF-specific } \\
\text { monoclonal antibody }\end{array}$} & RA & III & Completed & NCT01202760 \\
\hline & & & SLE & III & Recruiting & NCT01639339 \\
\hline
\end{tabular}

Status of studies identified in ClinicalTrials.gov current as of 8 Nov 2016, Abbreviations:

BAFF, B-cell-activating factor; CD40L, CD40 ligand; ICOS, inducible T-cell co-stimulator; 
ICOSL, ICOS ligand; LT, lymphotoxin; LT $\beta R$, LT $\beta$ receptor; RA, rheumatoid arthritis; SLE, systemic lupus erythematosus; SS, Sjögren syndrome.

\section{-ONLINE ONLY-}

\section{Author biographies}

Michele Bombardieri is a senior clinical lecturer in Experimental Medicine and Rheumatology at the William Harvey Research Institute at Queen Mary University of London, UK. He has a long-standing research interest in the pathogenesis of chronic inflammatory and autoimmune disorders, with a particular focus on the cellular and molecular mechanisms that regulate autoreactive B-cell activation and autoantibody production in ectopic germinal centres in the target organs of patients with rheumatoid arthritis and Sjögren syndrome.

Myles Lewis is a senior clinical lecturer in Experimental Medicine and Rheumatology at the William Harvey Research Institute at Queen Mary University of London, UK. His research focuses on understanding the effects of ubiquitylation pathways and of genetic variations in ubiquitylation genes on the immune system, with particular focus on B-cell differentiation and autoantibody production in autoimmune rheumatic diseases such as systemic lupus erythematosus, rheumatoid arthritis and other connective tissue disorders.

Costantino Pitzalis is Professor of Experimental Medicine and Rheumatology and Director of Research for Barts Health NHS Trust Emergency and Acute Medicine (ECAM) Clinical Academic Group and the Arthritis Research UK Experimental Arthritis Treatment Centre in London, UK. His research focuses on the cellular and molecular mechanisms of inflammation and autoimmunity in chronic arthritis, with a particular emphasis on translational research, biomarker discovery and experimental medicine.

\section{Subject categories}


Health sciences / Rheumatology / Rheumatic diseases / Connective tissue diseases / Systemic lupus erythematosus

[URI /692/4023/1670/122/1613]

Health sciences / Rheumatology / Rheumatic diseases / Rheumatoid arthritis

[URI /692/4023/1670/498]

Health sciences / Rheumatology / Rheumatic diseases / Connective tissue diseases / Sjögren's disease

[URI /692/4023/1670/122/1810]

Biological sciences / Immunology / Autoimmunity

[URI /631/250/38]

\section{ToC blurb}

\section{Ectopic lymphoid neogenesis in rheumatic autoimmune diseases}

Michele Bombardieri, Myles Lewis and Costantino Pitzalis

Ectopic lymphoid structures have been identified in the target organs of a subset of patients with rheumatic autoimmune diseases. This Review describes these structures and summarizes our current understanding of how they form, function and contribute to autoimmunity. 


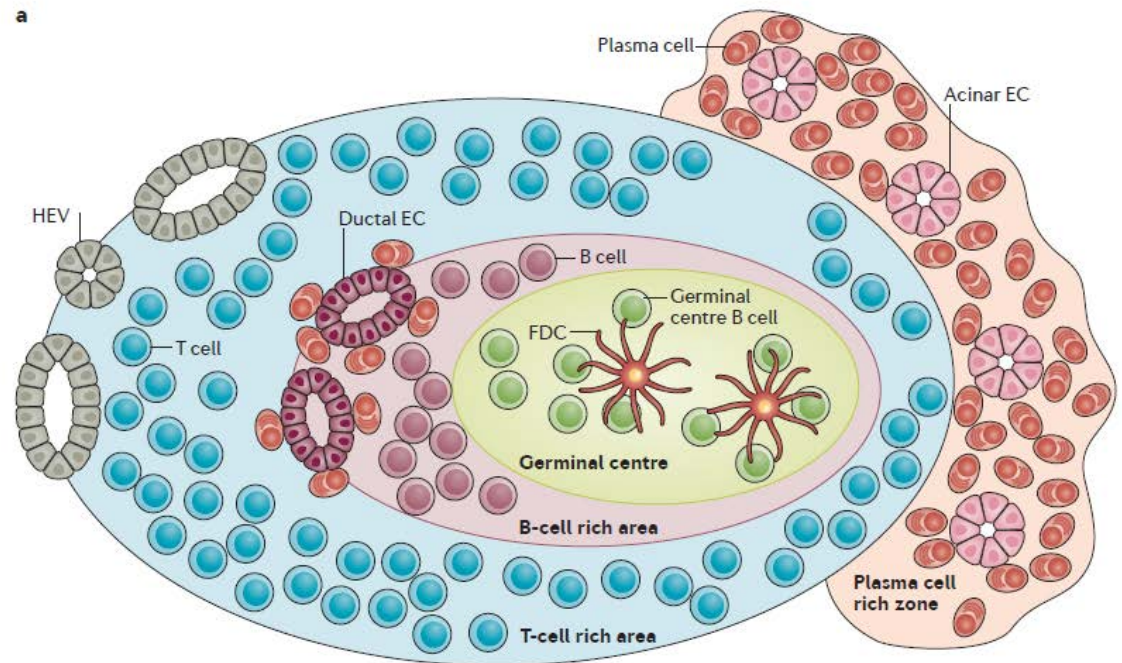

b $\quad \mathrm{CD} 3$

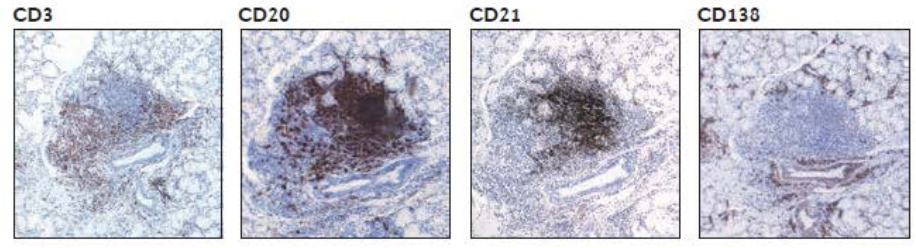

CD21 CD138 
Fig 2

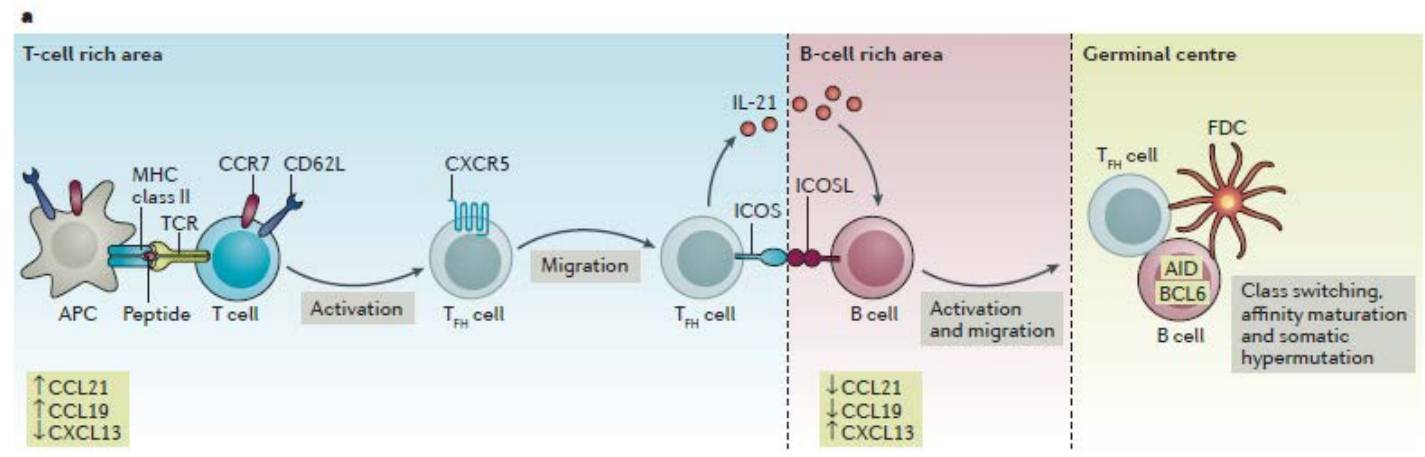

b $\quad$ CD20
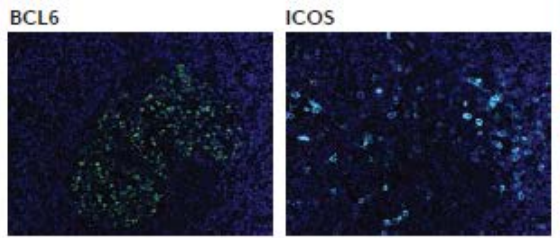

CD20/BCL6/ICOS
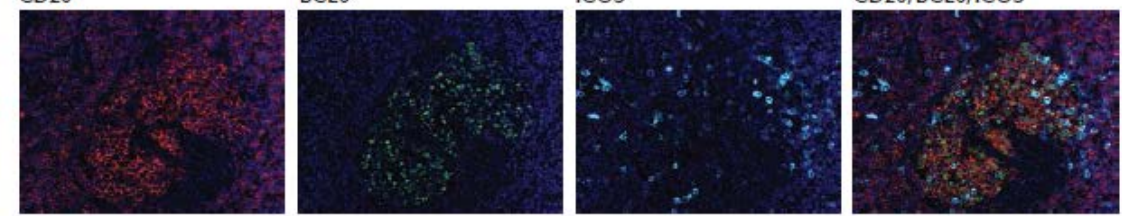
a Salivary gland of patient with SS
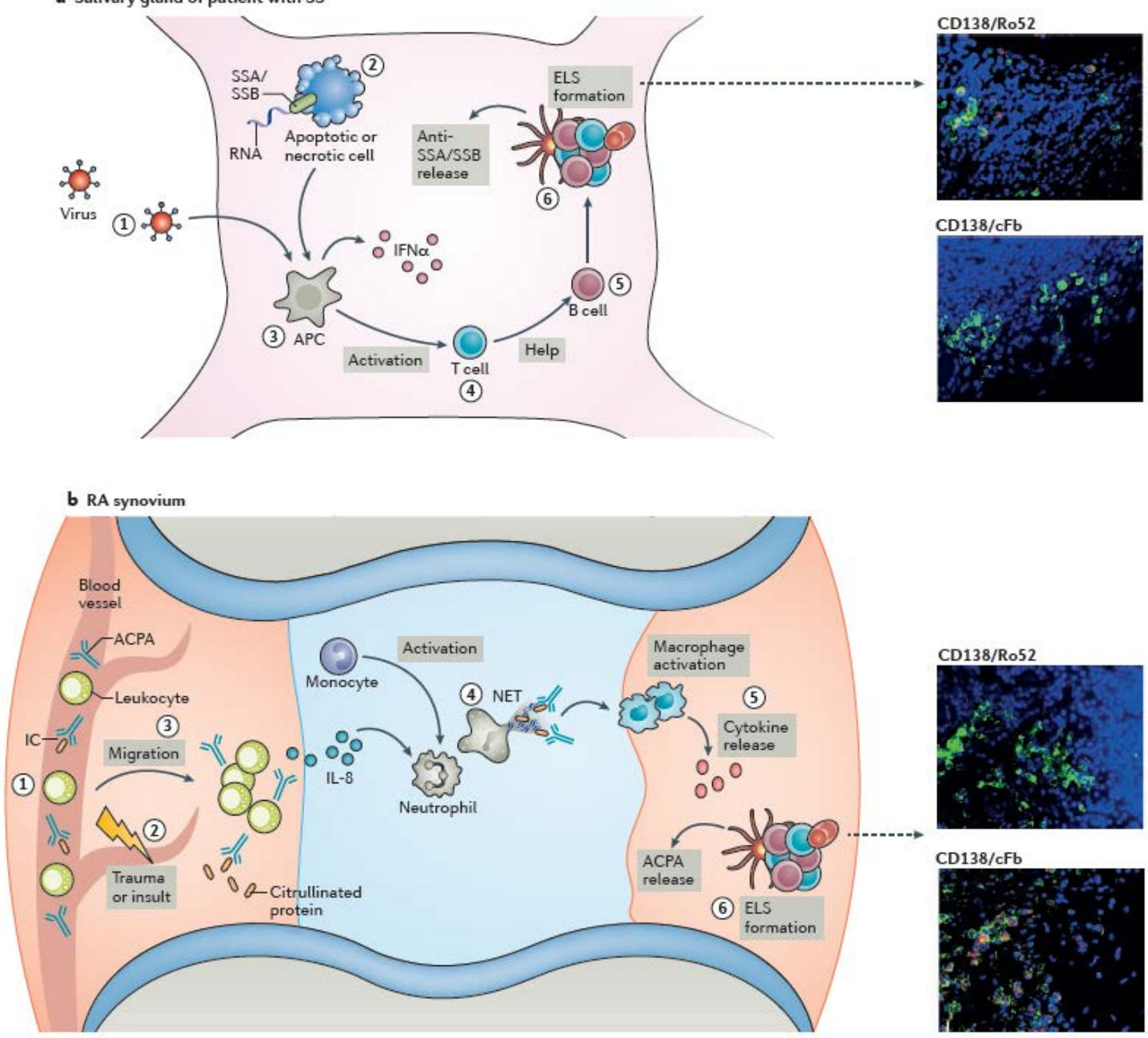